\title{
Fourier transform infra-red spectroscopy and flow cytometric assessment of the antibacterial mechanism of action of aqueous extract of garlic (Allium sativum) against selected probiotic Bifidobacterium strains
}

\author{
Jemma Booyens and Mapitsi Silvester Thantsha*
}

\begin{abstract}
Background: It is generally reported that garlic (Allium sativum) harms pathogenic but not beneficial bacteria. Although numerous studies supporting the alleged garlic effects on pathogens are available, there are limited studies to prove this claim for beneficial bacteria. We have recently shown that garlic exhibits antibacterial activity against probiotic bifidobacteria. The aim of the current study was to elucidate the mechanism of action of garlic clove extract (GCE) on Bifidobacterium bifidum LMG 11041, B. longum LMG 13197 and B. lactis Bb12 using Fourier transform infrared (FT-IR) spectroscopy and flow cytometry.

Methods: Cultures $\left(1 \times 10^{8} \mathrm{CFU} \mathrm{ml^{-1 }}\right)$ were individually incubated for $6 \mathrm{~h}$ at $37^{\circ} \mathrm{C}$ in garlic clove extract containing allicin at a corresponding predetermined minimum bactericidal concentration for each strain. For FTIR, an aliquot of each culture was deposited on $\mathrm{CaF}_{2}$ slide and vacuum dried. The slides were immediately viewed using a Bruker Vertex $70 \mathrm{~V}$ FT-IR spectrometer equipped with a Hyperion microscope and data analyzed using OPUS software (version 6, Bruker). Spectra were smoothed with a Savitsky-Goly function algorithim, base-line corrected and normalized. Samples for flow cytometry were stained using the Live/Dead BacLight bacterial viability kit L7012. Data compensation and analysis was performed using a BD FACSAria and FlowJo (version 7.6.1).

Results: Fourier transform infrared spectroscopy showed changes in spectral features of lipids and fatty acids in cell membranes, proteins, polysaccharides and nucleic acids. Spectral data as per principle component analysis (PCA) revealed segregation of control and GCE-treated cells for all the tested bifidobacteria. Flow cytometry not only showed increase in numbers of membrane damaged and possibly lysed cells after GCE treatment, but also displayed diffuse light scatter patterns for GCE treated cells, which is evidence for changes to the size, granularity and molecular content of the cells.

Conclusion: Garlic has multiple target sites in bifidobacteria, penetrating the cell membrane and entering the cytoplasm, where it causes changes to carbohydrates, fatty acids, proteins and nucleic acids. These changes, for example, modification of membrane properties, may prevent exposed bifidobacteria from colonizing the intestinal mucosa. Loss of colonization potential would render them less efficient as probiotics.
\end{abstract}

Keywords: Fourier transform infrared spectroscopy, Flow cytometry, Bifidobacterium, Garlic (Allium sativum), Probiotic

\footnotetext{
*Correspondence: mapitsi.thantsha@up.ac.za

Department of Microbiology and Plant Pathology, New Agricultural Sciences

Building Room 9-10, University of Pretoria, Lunnon road, Pretoria 0002,

South Africa
} 


\section{Background}

Bifidobacteria, used as probiotics, are added to a variety of different food products and pharmaceutical preparations due to their numerous health benefits $[1,2]$. In order to provide these health benefits, these bacteria need to be present in sufficient viable amounts within products, as well as be able to attach to and colonize the intestinal mucosa. It is therefore important to test susceptibility of these probiotic bacteria to compounds that may render them ineffective or decrease their capability to perform. Knowledge of the foods or food ingredients that may compromise viability of these bacteria is critical to their success in enhancing consumers' health. Garlic (Allium sativum) is a strong antibacterial agent and it is known to inhibit various pathogenic microorganisms [3].

We have recently revealed sensitivity of bifidobacteria to antibacterial effects of garlic [4], as well as initiated the process of elucidating its mechanism of action on these bacteria. Electron micrographs showed that garlic induced unusual morphological changes in bifidobacteria [5]. It is however not yet known whether garlic inhibition on probiotic cells is confined to the cell membrane or if there are other targets. We anticipate additional targets as allicin, the main active compound in garlic, has been reported to kill pathogens through total inhibition of RNA synthesis, partial inhibition of DNA and protein synthesis, and alteration of the electrochemical ability and induce apoptosis in cells [6-9]. It is also known to affect microbial lipid biosynthesis, signal transduction, as well as react with thiol-containing proteins [10-12].

Fourier transform infrared (FT-IR) spectroscopy is a fairly new technique used to study the entire molecular composition of microbial cells. It can "fingerprint' the entire cell and detect even the minimal cellular compositional changes that other methods fail to reveal [13]. This is possible because all functional groups of organic molecules are able to absorb IR light [14]. The infrared spectra of bacterial cells is able to reveal the biochemical composition of their cellular constituents which include the cell wall and membrane (composed of phospholipid bilayer, peptidoglycan and lipopolysaccharides), and the cytoplasm (fatty acids, water, nucleic acids, proteins and polysaccharides) $[14,15]$. This technique not only offers a rapid and non-invasive alternative to study changes or injury that takes place in bacterial cells, but it also requires minimal sample preparation [11].

Researchers elsewhere have used FT-IR spectroscopy to study the effect of different stress factors, injury or treatment with some antimicrobial compound on compositional changes of internal molecules of bacteria. It has recently been used to investigate the mode of action of bactericidal compounds and to determine changes in bacterial membrane fluidity and membrane phase behaviour in response to environmental stresses [13]. Zoumpopoulou et al. [14] used it to detect internal cellular changes in Salmonella enterica serovar typhimurium induced by exposure to antimicrobial compounds. Sub lethal thermal injury in S. enterica and Listeria monocytogenes, and cold stress injury in Campylobacter jejuni and Pseudomonas aeruginosa have also been identified using FT-IR spectroscopy $[11,15]$. Furthermore, it has been used to study chlorine-injured $P$. aeruginosa and Escherichia coli in water, radical induced damage of Micrococcus luteus and heat-killed E. coli O157:H7 in ground beef [16]. In studies closely related to our current study, it has been used to detect sub lethal damage in foodborne pathogens, such as C. jejuni, E. coli O157:H7 and L. monocytogenes, as a result to garlic exposure $[12,17]$.

Flow cytometry on the otherhand, is a technique that allows rapid analysis of individual cells, and can also simultaneously assess morphological and cellular functions [18]. It has been used to assess bacterial viability of probiotic products, dairy starter cultures [19] and to measure viability changes of different Bifidobacterium spp. [18,20]. Bunthof et al. [21] used flow cytometry to assess survival of different probiotic strains after their exposure to bile salt and acid.

This study therefore aimed to investigate the potential effects induced on macromolecules of bifidobacteria by GCE, using FT-IR and flow cytometry, in order to determine and better understand its mechanism and extent of damage on these bacteria.

\section{Methods}

\section{Culture and garlic clove extract preparation}

Bifidobacterium bifidum LMG 11041 and B. longum LMG 13197 strains (BCCM/LMG culture collection, Belgium) were revived as per manufacturer's specifications. Bifidobacterium lactis Bb12 was obtained from CHR-Hansen, Denmark. All cultures were grown in MRS-cys- $\mathrm{HCl}$ broth and incubated at $37^{\circ} \mathrm{C}$ for $48 \mathrm{~h}$ in anaerobic jars containing Anaerocult A gaspacks (Merck Ltd, Modderfontein, SA). The concentration of the cultures was then adjusted to 0.5 McFarland standard $\left(1 \times 10^{8} \mathrm{CFU} \mathrm{ml}^{-1}\right)$. Both the preparation of garlic clove extract (GCE) and spectrophotometric determination of the concentration of allicin, the major active compound in the extract, were performed as described previously [4]. Garlic clove extract was added to $1 \mathrm{ml}$ of each culture up to a final allicin concentration equivalent to the predetermined minimum bactericidal concentrations of 99.4, 198.7 and $39.8 \mu \mathrm{g} \mathrm{ml}^{-1}$ for B. bifidum LMG 11041, B. lactis Bb12, and B. longum LMG 13197, respectively. Cultures were then incubated at $37^{\circ} \mathrm{C}$ for $6 \mathrm{~h}$.

\section{FT-IR spectroscopy \\ Preparation of bacteria}

Bacterial cells were recovered from prepared $1 \mathrm{ml}$ broth cultures by centrifugation at $13400 \mathrm{rpm}$ for $15 \mathrm{~min}$. The 
supernatant was discarded and pellet was washed twice in $1 / 4$ strength Ringer's solution. The pellet was then resuspended in $1 \mathrm{ml}$ distilled water, ready for sample preparation and measurements. The average cell concentration was kept constant at $1 \times 10^{8} \mathrm{CFU} \mathrm{ml}^{-1}$ in order to generate consistent FT-IR signals. Samples for FT-IR were prepared according to Marcotte et al. [22] with slight modifications. A $5 \mu \mathrm{l}$ aliquot of each bacterial sample was deposited onto a $\mathrm{CaF}_{2}$ slide and air-dried at room temperature under low vacuum for $15 \mathrm{~min}$. A further $2 \mu \mathrm{l}$ of sample was deposited on top of the dried sample to form a homogenous dried film of cells. Samples were analyzed directly after preparation to prevent any changes associated with aging of the samples.

\section{Spectral measurements and data analysis}

A Bruker Vertex 70 V FT-IR spectrometer (Bruker Optics, Germany), equipped with a Hyperion microscope attachment was used. The bacterial coated $\mathrm{CaF}_{2}$ slides were placed under the microscope objective and IR spectra were recorded in transmission mode from 4000 to $850 \mathrm{~cm}^{-1}$ at a spectral resolution of $4 \mathrm{~cm}^{-1}$. Fifteen spectra for each sample were obtained at room temperature. A total of 45 spectra $(3 \times 15)$ for each treatment were obtained. Experiments were performed in triplicate. OPUS software version 6 was used to perform data analysis. Spectra were smoothed with a Savitsky-Goly function algorithim with 25 smoothing points, base-line corrected and normalized. Principle component analysis (PCA) was used on raw data to separate and group control and GCE-treated bacterial spectra to illustrate differences between the two data sets.

\section{Flow cytometry}

\section{Preparation of bacteria}

Bacterial cells from prepared $1 \mathrm{ml}$ broth cultures were harvested by centrifugation at $13400 \mathrm{rpm}$ for $15 \mathrm{~min}$ and the pellet washed twice with $1 / 4$ Ringers solution. Cells were resuspended in phosphate buffered saline (PBS) and the concentration adjusted to $10^{8}$ cells $\mathrm{ml}^{-1}$. Live untreated cells in their mid-exponential phase and heatkilled $\left(70^{\circ} \mathrm{C}\right.$ for $\left.30 \mathrm{~min}\right)$ cells were used as negative and positive controls, respectively.

\section{Staining of bacteria}

Samples (live, heat killed, and GCE treated) of each Bifidobacterium were stained with the Live/Dead BacLight bacterial viability kit L7012 (Molecular Probes, Netherland). Three replicates of each control were individually stained with $1.5 \mu \mathrm{l}$ (1:20 dilution) of PI, SYTO9 or a 1:1 mixture of SYTO9 and PI. These samples were used to set up the protocol, and to differentiate between live, dead and compromised cells. Flow cytometric detectors and compensation settings for the different quadrants were performed using control samples. Dual staining was also performed for GCE treated samples. All the samples were then incubated in the dark for $15 \mathrm{~min}$. Thereafter, they were centrifuged at $13400 \mathrm{rpm}$ for $10 \mathrm{~min}$ and pellets resuspended in PBS and placed on ice before analysis.

\section{Data capture and analysis}

A BD FACSAria (BD Biosciences, USA), fitted with four argon lasers $(488 \mathrm{~nm}, 633 \mathrm{~nm}, 405 \mathrm{~nm}$ laser and $375 \mathrm{~nm}$ near UV laser) was used. BD FACSflow was used as sheath fluid and 10000 events per sample were counted. Green fluorescence (SYTO9) was detected through a $530 \mathrm{~nm}, 30$ nm-bandwidth band-pass filter which amounts to a range of 675-715 nm (FITC). Red fluorescence (PI) was detected through a $695 \mathrm{~nm}, 40 \mathrm{~nm}$ band-pass filter (Per-C-P), amounting to a range of $515-545 \mathrm{~nm}$. A combination of forward scatter (FSC) and sideward scatter (SSC) was used to discriminate bacteria from background. Experiments were performed in triplicate and data compensation and analysis was performed using FlowJo Version 7.6.1.

\section{Results and Discussion FT-IR spectroscopy}

Fourier transform infra-red spectra for most bacteria have four distinguishable regions. Region I (3000-2800 $\mathrm{cm}^{-1}$ ) represents cell membrane fatty acids, with three noticeable peaks $\left(2960,2925\right.$, and $\left.2860 \mathrm{~cm}^{-1}\right)[11,14]$. Region II $\left(1700-1500 \mathrm{~cm}^{-1}\right)$ shows amide I $\left(1650 \mathrm{~cm}^{-1}\right)$ and amide II $\left(1550 \mathrm{~cm}^{-1}\right)$ bands of proteins and peptides [16]. Region III (1500-1200 $\left.\mathrm{cm}^{-3}\right)$ corresponds to fatty acids as well as proteins and phosphate-carrying molecules. Three major peaks at $1455 \mathrm{~cm}^{-1}, 1400 \mathrm{~cm}^{-1}$ and $1240 \mathrm{~cm}^{-1}$ depict changes to lipids and proteins; carbohydrates and nucleic acids or phospholipids, respectively. Bands at $1080 \mathrm{~cm}^{-1}$ are also related to nucleic acids (11). Region IV (1200-900 $\mathrm{cm}^{-3}$ ) shows absorption bands typical of polysaccharides or carbohydrates of microbial cell walls with an absorption peak between 1100-950 $\mathrm{cm}^{-1}[14,16]$.

The spectra obtained for all the tested Bifidobacterium strains were similar to those previously described for other bacteria $[11,14,23]$. Strong absorptions were obtained for all four spectral regions $\left(4000-850 \mathrm{~cm}^{-1}\right)$ representing the main components of a cell. Control and GCE-treated Bifidobacterium samples showed discrepancies in spectra obtained, as discussed in detail for each tested strain below.

\section{Bifidobacterium bifidum LMG 11041}

Spectral features of control and GCE treated samples were different (Figure 1). There were shifts at all major peaks, 3285, 2930, 1655, 1550, 1452, 1400, 1238, 1078, and $913 \mathrm{~cm}^{-1}$ (Figure 1), indicating changes in the biochemical composition of cells due to exposure to GCE. Shifts at peaks $3285 \mathrm{~cm}^{-1}$ indicate changes to proteins and polysaccharides while shifts at peak $2930 \mathrm{~cm}^{-1}$ correspond to changes to lipids. In addition, there was an 


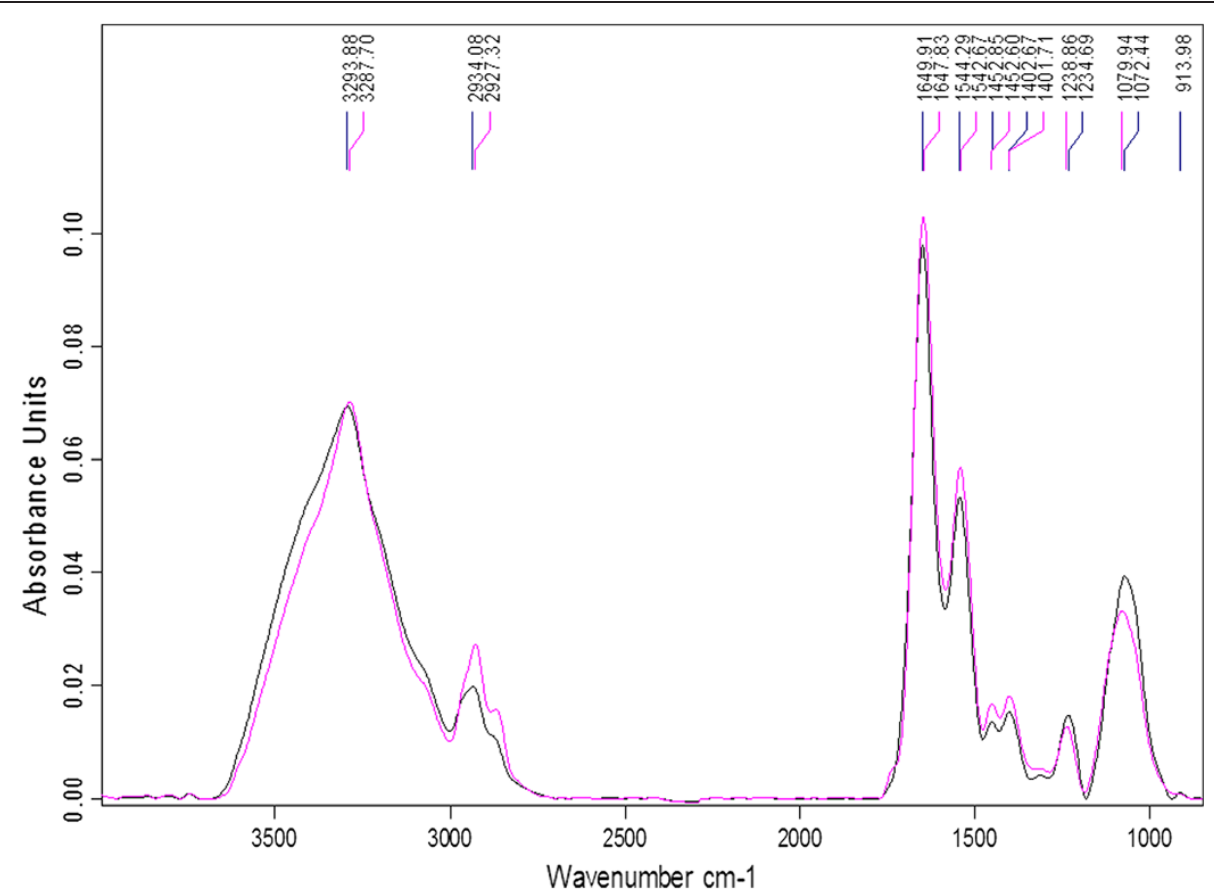

Figure 1 Fourier transform infra-red spectra of B. bifidum LMG 11041 samples, control: black; garlic clove extract-treated: pink.

increase in spectral frequency at peak $2934 \mathrm{~cm}^{-1}$, which may indicate an increase in membrane fluidity as well as a conformation disorder of the acyl chains of the cell membrane phospholipids [13]. These results suggest a change in properties of cell membranes of treated cells. Minor shifts at peaks $1649 \mathrm{~cm}^{-1}$ and $1544 \mathrm{~cm}^{-1}$ (Amide I and II) were also observed, with an associated increase in intensity of spectral features of these two peaks for GCE-treated cells compared to the control. This could indicate an increase in polysaccharides, which serve as a mechanism of survival for cells to down regulate functions to save energy and protect themselves from stress [11]. The biggest shifts occurred at peaks $1238 \mathrm{~cm}^{-1}$ and $1079 \mathrm{~cm}^{-1}$, which represent phosphodiesters and nucleic acids, and carbohydrate regions in the cell wall, respectively. There were major decreases in spectral intensities of GCE treated cells for these peaks, which could indicate a reduction in viable counts, prevention of cell growth or cell death [11]. Allicin, the main active compound of garlic, can readily pass through cell membranes and affect lipid and fatty acid biosynthesis causing changes in viability of cells [10]. Changes in the nucleic acid region corresponds to published literature reports stating that allicin completely inhibits RNA synthesis and partially inhibits protein and DNA synthesis [6]. Furthermore, the spectra for control showed a clear peak at $913 \mathrm{~cm}^{-1}$, which disappeared after treatment of cells with GCE. This may indicate damage to the phospholipids in the cell wall. Similar observations were reported for Escherichia coli and Listeria monocytogenes due to their exposure to garlic [17].

\section{Bifidobacterium longum LMG 13197}

Similar to what was observed for B. bifidum LMG 11041, there were considerable shifts in the spectra at peaks $3291 \mathrm{~cm}^{-1}$ and $2928 \mathrm{~cm}^{-1}$ for GCE-treated cells (Figure 2). Compared to control samples, prominent changes were observed in region $3600-2800 \mathrm{~cm}^{-1}$, with decreased band area and intensities at peaks $3291 \mathrm{~cm}^{-1}$ and $2928 \mathrm{~cm}^{-1}$ (representing lipids), which could be related to a reduction in cell viability. A decrease in spectral band intensity is an indication of cell death. Similar results were previously reported for E. coli O157:H7 that were subjected to cold stress and low nutrient media [11]. Environmental stresses have been shown to induce changes in the cell membrane lipid composition [24]. Furthermore, allicin disrupts microbial lipid and fatty acid formation, thereby causing changes in viability of cells [10]. An increase in intensities of both amide bands for GCE-treated cells was also observed. These cells also showed a decrease in spectral intensities in regions $1490 \mathrm{~cm}^{-1}-1260 \mathrm{~cm}^{-1}$ and $1074 \mathrm{~cm}^{-1}$, coupled with a reduction in band area at peak $1074 \mathrm{~cm}^{-1}$, changes usually associated with cell death or cessation of growth [11]. Shifts at peaks $1236 \mathrm{~cm}^{-1}$ and $1074 \mathrm{~cm}^{-1}$ suggest denaturation of the phosphodiester backbone of nucleic acids, thus damage to DNA and RNA. The peaks observed at $914 \mathrm{~cm}^{-1}$ and $871 \mathrm{~cm}^{-1}$ for controls were absent in 


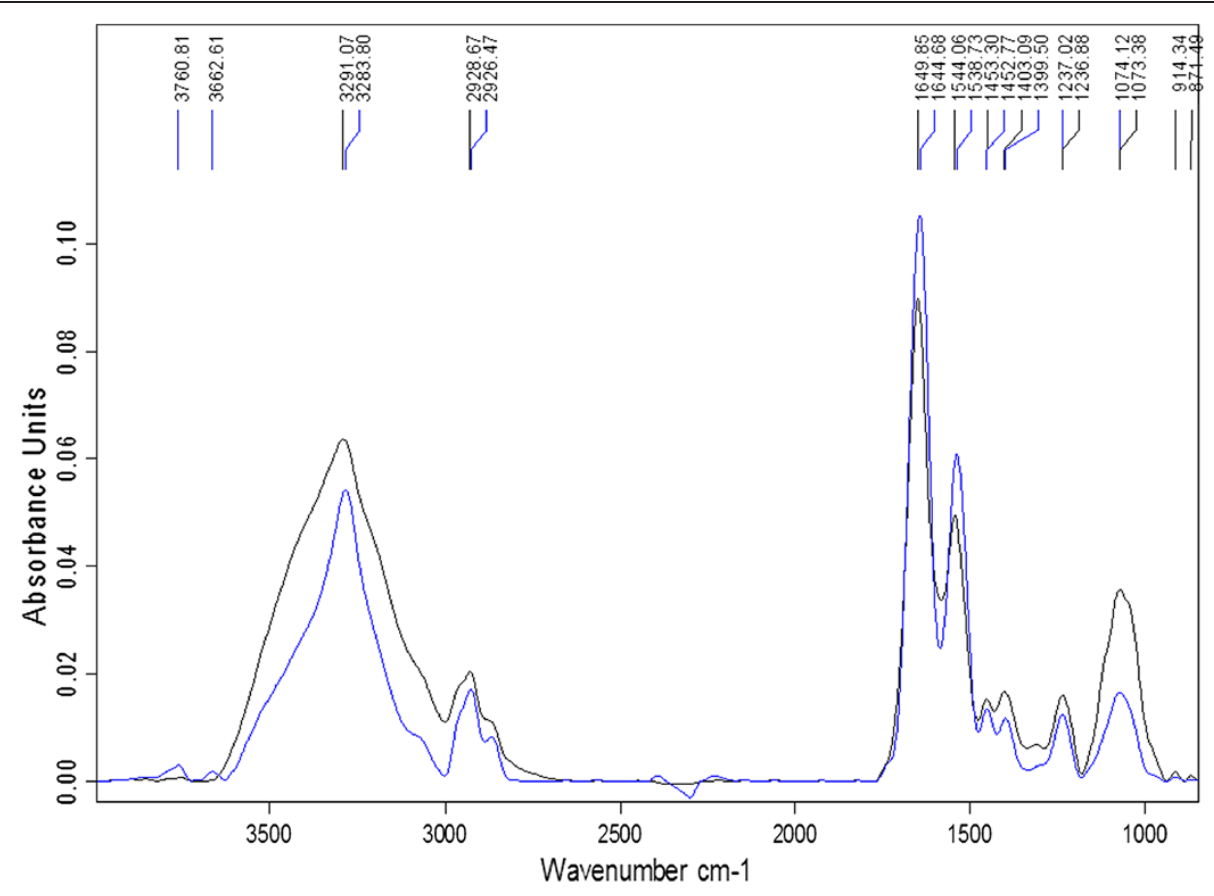

Figure 2 Fourier transform infra-red spectra of $B$. longum LMG 13197 samples, control: black; garlic clove extract-treated: blue.

GCE-treated cells, indicating changes to the structure of the bacterial envelope polysaccharides [23].

\section{Bifidobacterium lactis $\mathrm{Bb} 12$}

There were minimal discernible differences between spectral features for control and GCE treated B. lactis Bb12 samples at peaks $2930 \mathrm{~cm}^{-1}$ (lipids), $1648 \mathrm{~cm}^{-1}$ (Amide I), $1542 \mathrm{~cm}^{-1}$ (Amide II), $1453 \mathrm{~cm}^{-1}$ (proteins) and $1235 \mathrm{~cm}^{-1}$ (phosphodiesters) (Figure 3). The observed visual similarities between FTIR spectra for control and GCE treated $B$. lactis is attributed to its intrinsic resistance of detrimental factors, specifically its relative resilience to antibacterial

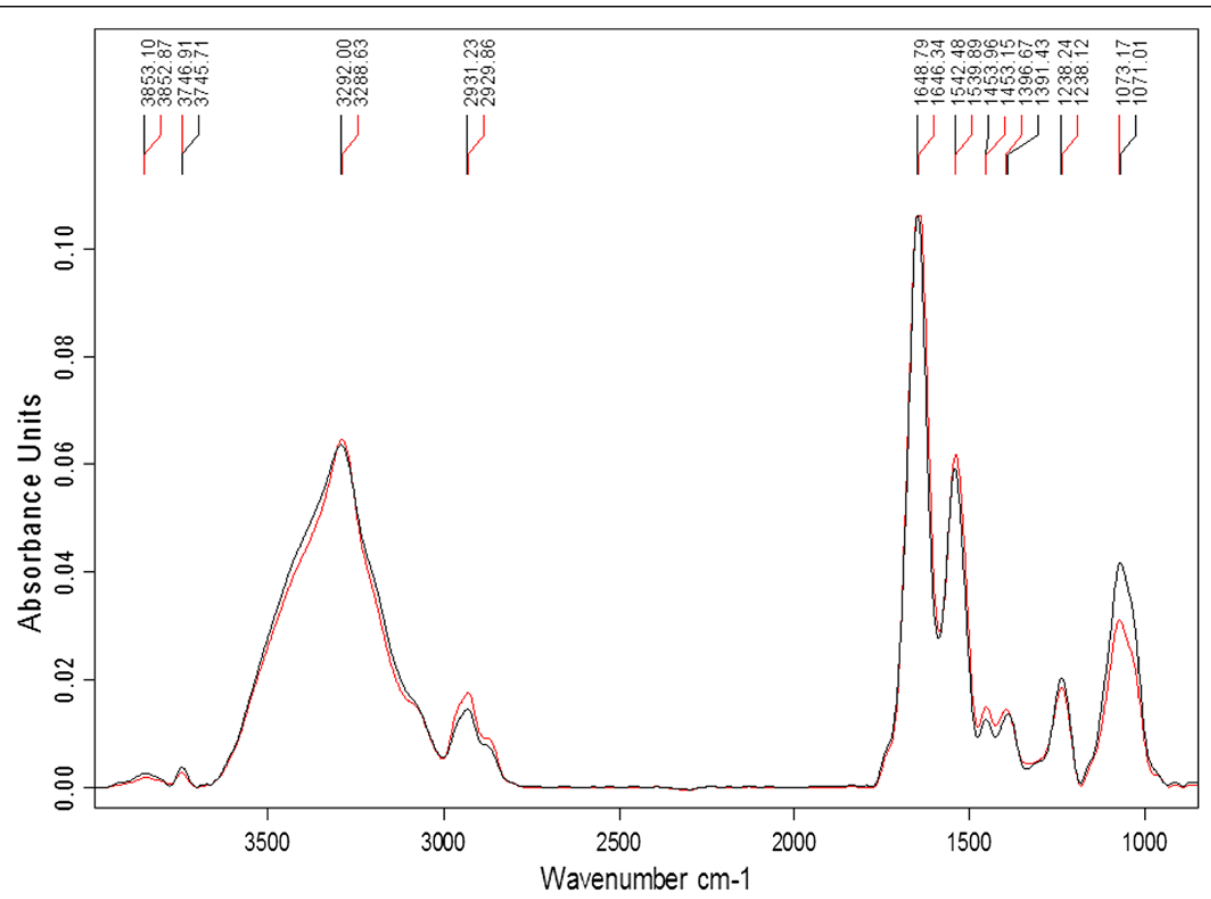

Figure 3 Fourier transform infra-red spectra of $B$. lactis Bb12 samples, control (black); garlic clove extract-treated (red). 
effects of garlic, compared to other bifidobacteria [4]. However, a slight decrease in spectral intensity around the lipid regions $\left(2929 \mathrm{~cm}^{-1}\right)$ and a reduction in intensity around the phosphodiester region $\left(1235 \mathrm{~cm}^{-1}\right)$ for GCEtreated cells compared to controls were noticeable. As already mentioned, these are changes attributed to a decrease in cell viability [11]. According to Al-Qadiri et al. [15], a change in the spectral regions at peak $1235 \mathrm{~cm}^{-1}$ indicates nucleic acid denaturation. A major decrease in intensity for this strain was observed at peak $1073 \mathrm{~cm}^{-1}$, which is within a region corresponding to nucleic acids. Therefore, these observations once again indicated that GCE altered RNA and DNA, as was observed with the other Bifidobacterium strains tested in this study, although the change was less pronounced for this strain, and reported for other bacteria elsewhere, a damage that may eventually lead to cessation of growth or microbial death.

\section{Principle component analysis of FTIR spectra}

Principle component analysis has been extensively used for interpretation of infrared spectra in microbiology, medicine, agricultural and food sciences. It reduces a multidimensional data set to its most dominant features, removes random variation while maintaining the relevant variations between data points $[16,25]$. It shows whether there are definite clusters in the data and describes similarities or differences from multivariate data sets [25]. In this study, PCA was performed concurrently for all four FTIR spectral regions described, as well as for the separate regions. Groupings of the spectra representing differences or similarities among the regions were then used to compare molecular compositions of control and GCE-treated bifidobacteria.

Figure 4 shows the PCA of the first derivative and multiplicative scatter correction of B. bifidum LMG 11041.

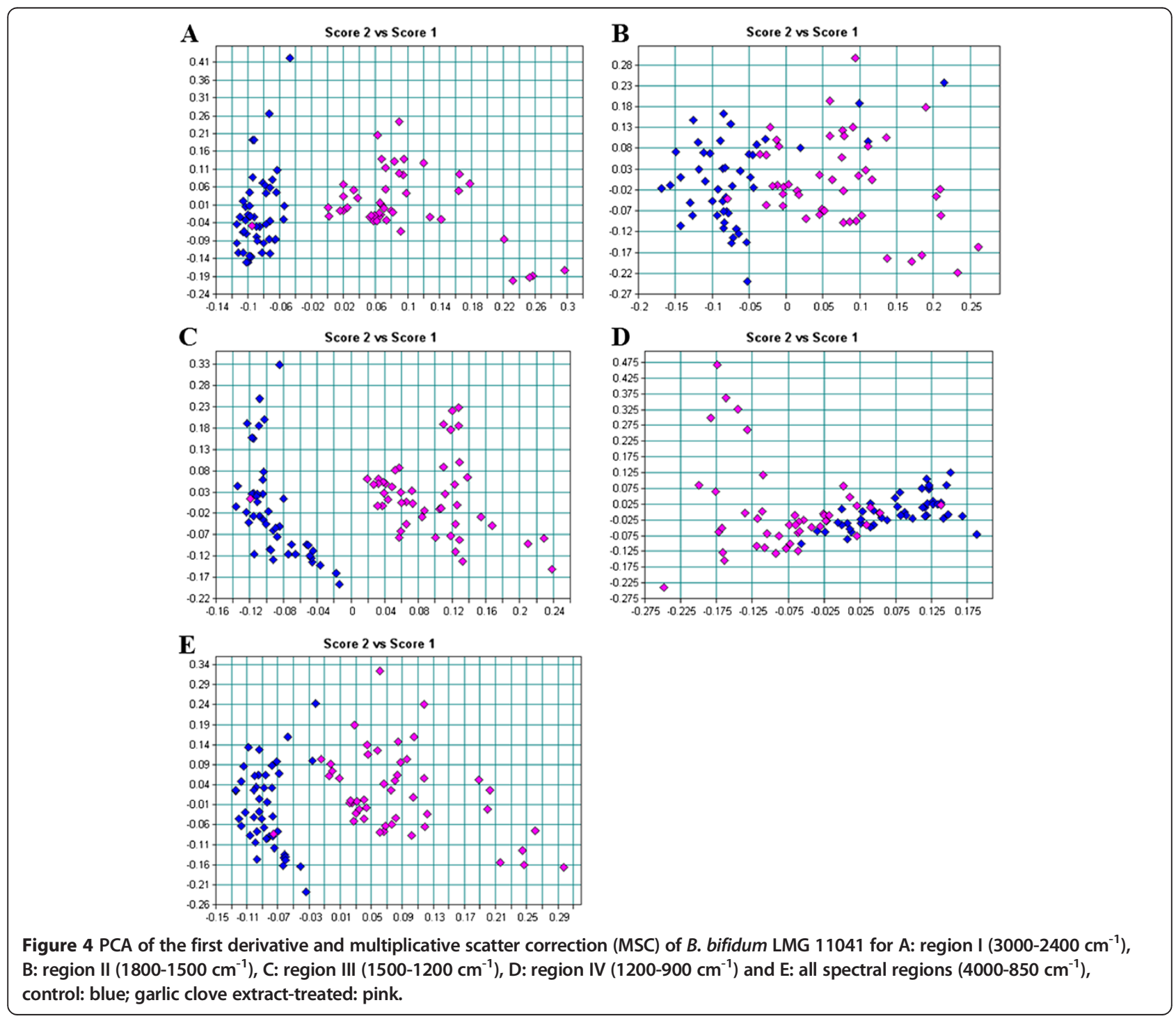


Comparison of whole spectra patterns of the control and GCE-treated samples showed segregation between these two groups of samples (Figure 4E). However, upon closer inspection, distinct separation between clusters in region I (Figure 4A) and III (Figure 4C) were observed than in other regions, with differences better distinguished in region III than region I. There was no distinct clustering for in spectral regions II and IV (Figure 4B and D). These findings show that the most significant changes induced by GCE occurred in the region representing cell structure proteins and phosphodiesters associated with phospholipid bilayers, while other cellular constituents were less affected. This further explains our previous reports of unusual morphological changes for this strain [4].

Separation of spectra between B. longum LMG 13197 control and GCE-treated samples over all regions were observed (Figure 5). Major spectral differences were observed in regions I, II and III (Figure 5B-D) than in region IV. This indicated that for B. longum LMG 13197, polysaccharides of the cell wall were less affected than the other cellular components. Garlic clove extract caused more biochemical changes in this strain compared to $B$. bifidum LMG 11041.

Clear separations with distinct sample clusters were observed for control and GCE-treated B. lactis Bb12 throughout all the spectral regions (Figure 6). However, there were fewer differences between control and GCE-treated samples in regions III and IV as these clusters were closer to each other (Figure 6). Significant differences were observed within the lipid and protein regions, indicated by the more isolated clusters (Figure 6B-C). Damage was confined to the cell wall for this strain whereas for the more sensitive strains (B. bifidum LMG 11041 and B. longum LMG 13197), it extended to the nucleic acids.

In summary, PCA confirmed distinctive features of the FT-IR spectra among Bifidobacterium cells, indicated by
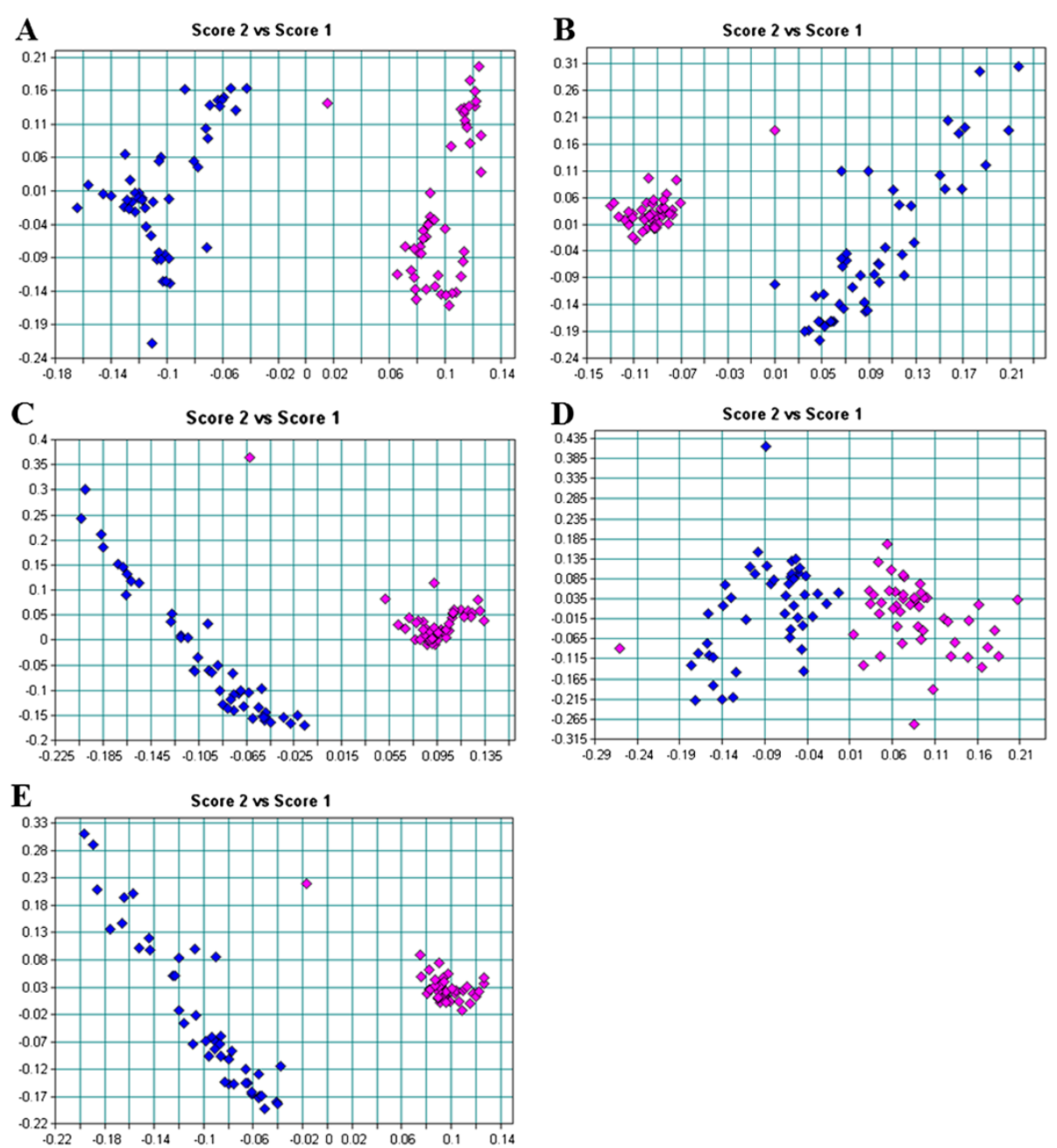

Figure 5 PCA of the first derivative and multiplicative scatter correction (MSC) of B. longum LMG 13197 for A: region I ( $\left.3000-2400 \mathrm{~cm}^{-1}\right)$, B: region II (1800-1500 cm $\left.\mathrm{cm}^{-1}\right)$, C: region III $\left(1500-1200 \mathrm{~cm}^{-1}\right)$, D: region IV $\left(1200-900 \mathrm{~cm}^{-1}\right)$ and E: all spectral regions $\left(4000-850 \mathrm{~cm}^{-1}\right)$, control: blue; garlic clove extract-treated: pink. 


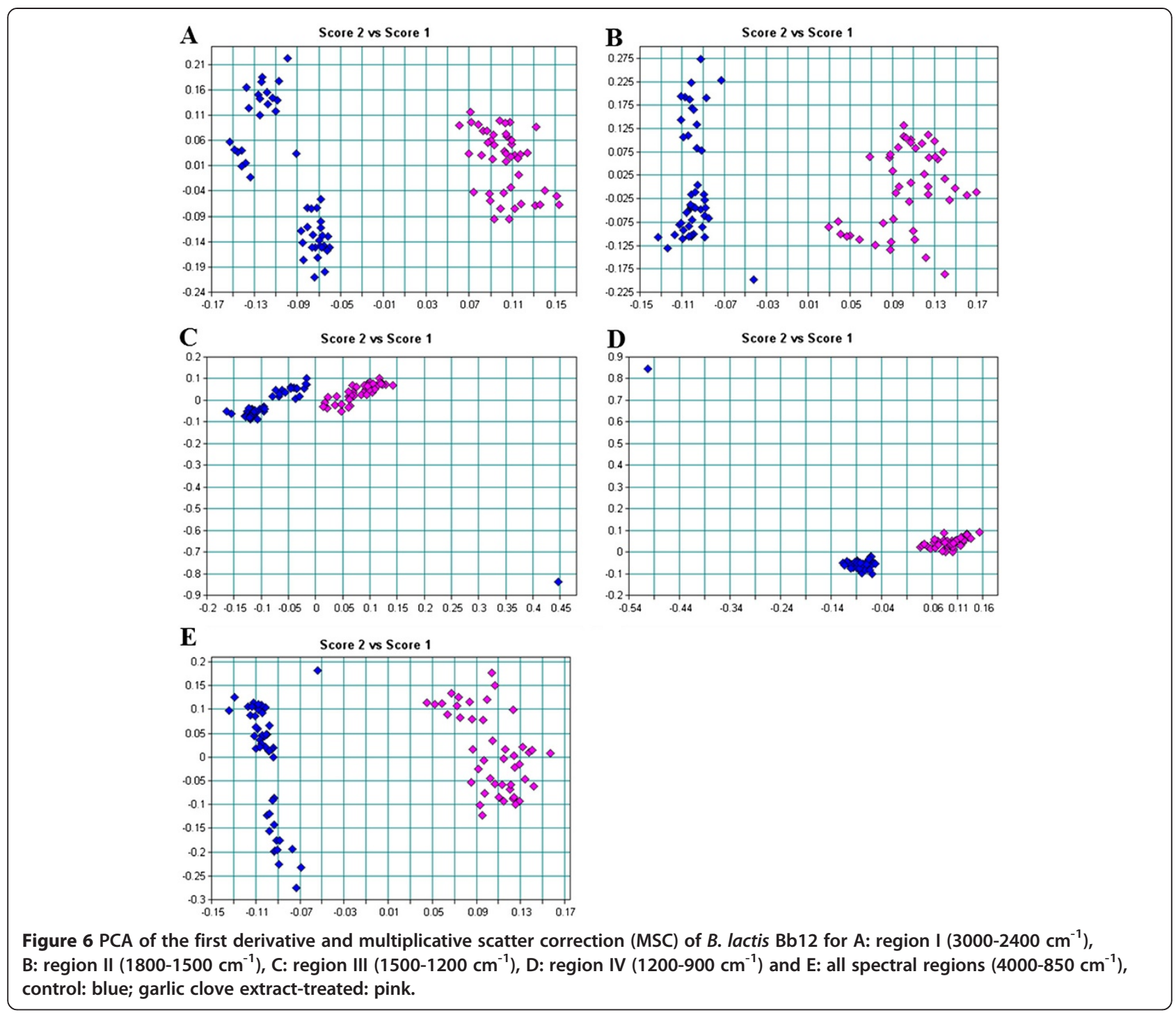

clear segregations with distinct sample clusters in most if not all of the spectral regions between control and GCE-treated cells. In all the tested cells, exposure to GCE resulted in significant changes in lipids or fatty acids in the cell membrane, structural proteins and phosphodiesters associated with phospholipid bilayer. Noteworthy differences between control and GCE-treated cells were also observed in the amide groups of proteins, the nucleic acids as well as in polysaccharides of the cell walls for $B$. longum LMG 13197 and B. lactis Bb12.

\section{Flow cytometric analysis}

Double staining of Bifidobacterium cells with PI and SYTO9 was used to determine the effect of GCE on the cell membrane integrity, thereby giving an indication of whether the cell is viable, dead or damaged. Intact, undamaged cell membrane excludes the nucleic acid dye, PI, while damage permeabilizes it to this stain, which upon entry into the cells binds to nucleic acids, resulting in red fluorescence. Propidium iodide is therefore used as a marker for dead cells. SYTO9 stains all cells in a population, whether they are alive or dead [26]. It is however displaced by PI from the nucleic acids of damaged cells due to the higher affinity of the latter for DNA [21]. These stains have been used in studies on lactic acid bacteria to differentiate between healthy and damaged cells $[19,21,27]$. Figure 7 depicts the dot plots obtained for the different Bifidobacterium strains before and after treatment with GCE. Different quadrants were set to represent the following populations of cells: quadrant 1 (Q1): live SYTO9-stained cells, quadrant 2 (Q2): double-stained membrane damaged cells, quadrant 3 (Q3): dead PIstained cells and quadrant 4 (Q4): unstained cells. There were noticeable differences between control and GCE treated cells for all the tested Bifidobacterium strains. The percentage of viable cells of B. bifidum LMG 11041 

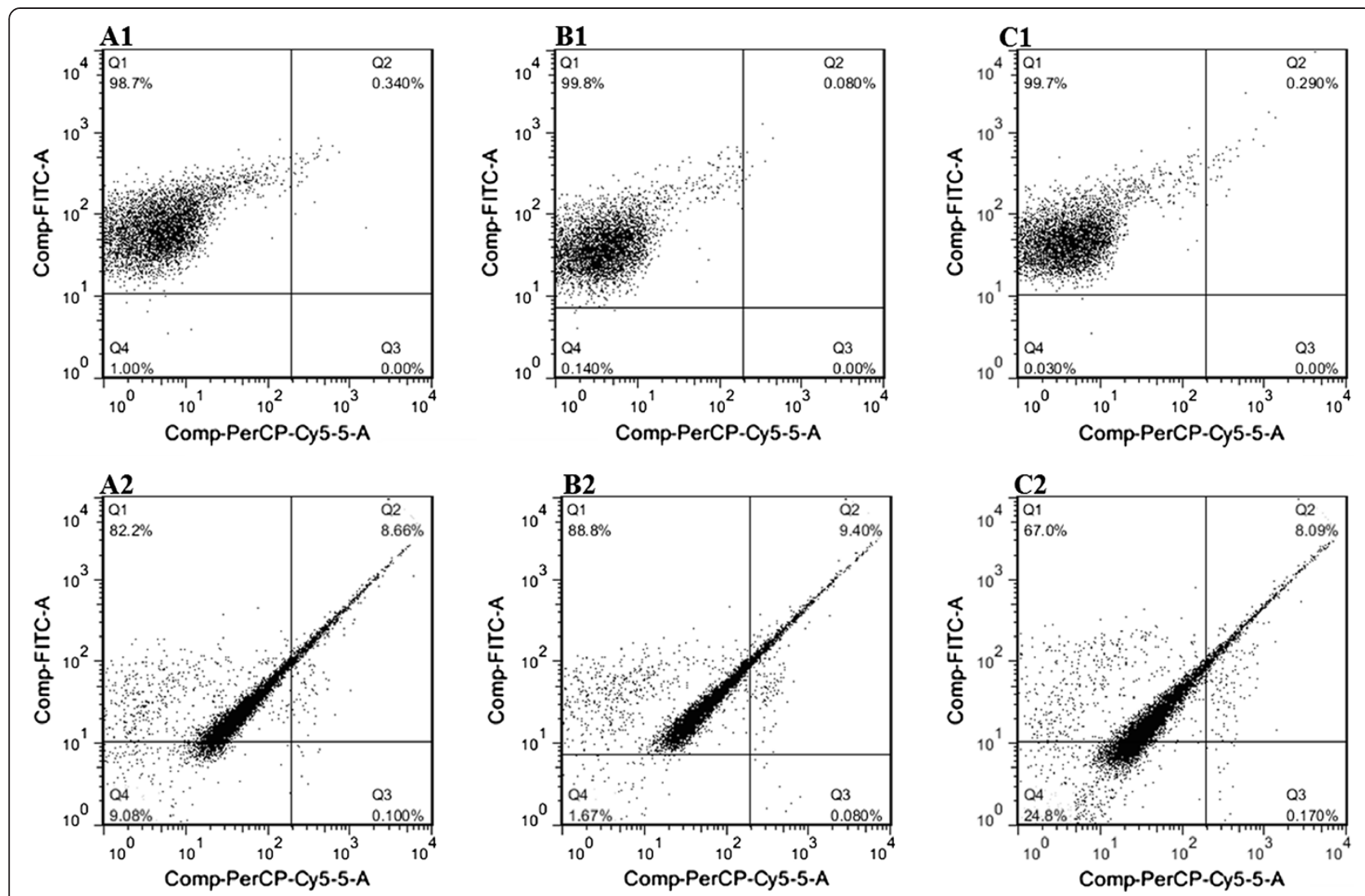

Figure 7 Flow cytometry dot plots of B. bifidum LMG 11041 (A1) control, (A2) garlic clove extract-treated; B. longum LMG 13197 (B1) control, (B2) garlic clove extract-treated; B. lactis Bb12 (C1) control, (C2) garlic clove extract-treated.

cells decreased by about $17 \%$ after GCE treatment while increases of 8.32, 0.1 and 8.08\% were observed in Q2, Q3 and Q4, respectively (Figure 7, A1 and A2). Bifidobacterium longum LMG 13197 followed a similar trend to $B$. bifidum LMG 11041. The viable cell population decreased by $11 \%$ after GCE treatment, whereas number of damaged cells in Q2 increased by 9.3\% (Figure 7, B1 and B2). The major difference between B. longum LMG 13197 and B. bifidum LMG 11041 was that an increase in the percentage of unstained $B$. bifidum cells, was less than that observed for B. longum by $7.4 \%$. These results suggest that this strain was less susceptible to antibacterial effects of GCE. The viable population of B. lactis Bb12 was only $67 \%$ after GCE treatment compared to 99.7\% for control sample. However, for this strain, the reduction in percentage of viable cells was accompanied by a substantial increase in percentage $(24.77 \%)$ of unstained cells (Figure 7, C1 and C2), an increase higher than that observed for each of the other two strains by more than $15 \%$. This result did not correspond to data obtained by FTIR, which indicated less damage to B. lactis Bb12. However, the percentage of cells having membrane damage was comparable to that obtained for the other two strains. Flow cytometric data results confirmed that all three Bifidobacterium strains tested were susceptible to GCE. An increase in percentage of cells in Q2 is evident of progressive cell damage and membrane deterioration. Similar flow cytometric data for bifidobacteria exposed to bile salt stress was obtained by Ben Amor et al. [28]. Ananta et al. [27] also found cell membrane damage using flow cytometry to analyze viability of Lactobacillus rhamnosus after spray drying.

A definite reason for the presence of unstained cells in Q4 is unknown, but it could be attributed to one or a combination of the following. Firstly, unstained cells could correspond to the cells that have undergone severe lysis and thus lost their nucleic acids, thereby rendering them unstainable [29]. These 'ghost cells' have been described by other researchers elsewhere [30,31]. Previous studies have also reported that garlic causes cell lysis. Kim et al. [32] reported cell wall lysis in Listeria monocytogenes cells treated with garlic shoot juice. Allicin, the major active compound of garlic, has been reported have the ability to pass through phospholipid membranes, causing cell membrane damage and eventually cell lysis and death [8]. Secondly, these could be cells that clumped together or formed interlaced chains which, according to Hayouni et al. [33], may decrease staining accuracy. 
Differences in shape and density of the populations' light scatter patterns before and after exposure to GCE were also observed for all the tested Bifidobacterium strains. After GCE treatment the light scatter patterns became less diffuse and more concentrated, indicating a change in size, granularity and molecular content of the cells (Figure 7). Similar results were also observed in Candida albicans by Grannoum 1988, where the change in structure and integrity of the outer membrane was attributed to a decrease in lipid content of the membrane in the presence of garlic [32]. A different light scatter pattern obtained after exposure of cells to GCE could be due to a change in size or cellular structure and external morphology, whereby cells change from rod to coccoid shape. We have recently reported a change of bifidobacteria from rod to cocci shaped cells with cross- walls due to treatment with GCE [4]. Similar results were reported by Schenk et al. [34] for E. coli and L. innocua cells exposed to UV-C light. Young [35] also showed that typical rod-shaped Bifidobacterium spp. became coccoid under stress.

\section{Conclusions}

The mechanism of action of garlic towards bifidobacteria is similar to that which was reported for pathogenic bacteria. Bacterial growth inhibition and death occurs due to modifications to secondary structure proteins, fatty acids and phospholipids in the cell membrane as well as nucleic acids. Changes to the membrane properties may therefore prevent these probiotic Bifidobacterium strains from colonizing the intestinal mucosa and thereby hinders them from delivering the beneficial effects. Hence, we suggest that precaution be taken with simultaneous use of probiotic bifidobacteria and garlic. Future studies could focus on sorting the GCE modified cells and comparing their physiological properties to that of their original counterparts not exposed to garlic, to establish whether these damaged but live cells can still deliver their probiotic effects to the consumer. Furthermore, the effect of food matrices on allicin levels, as well as how long allicin persists in the gastrointestinal tract, needs to be investigated.

\section{Competing interests}

The authors declare that they have no competing interests.

\section{Authors' contributions}

MST conceived of the study and participated in design of the study, as well as reviewed the manuscript. JB carried out the experiments and analysis of data, and wrote the first draft of the manuscript. Both authors read and approved the final manuscript.

\section{Acknowledgements}

Thanks are due to the National Research Foundation and University of Pretoria for funding this project. The authors are also grateful to $\mathrm{Dr} L$. Prinsloo, Department of Physics, University of Pretoria, for her technical assistance with FT-IR spectroscopy, Mr W. Barnes, Dr A. Smit and Mrs
P. Kapewangolo for their technical assistance with the flow cytometer and Mrs K. Le Roux for helping with Flowjo data analysis.

Received: 6 January 2014 Accepted: 30 July 2014

Published: 6 August 2014

\section{References}

1. Mattarelli P, Biavati B, Pesenti M, Crociani F: Effect of growth temperature on the biosynthesis of cell wall proteins from Bifidobacterium globosum. Res Microbiol 1999, 150:117-127.

2. Gueimonde M, Noriega L, Margolles A, de los Reyes-Gavilan CG, Salminen S: Ability of Bifidobacterium strains with acquired resistance to bile to adhere to human intestinal mucosa. Int J Food Microbiol 2005, 101:341-346.

3. Goncagul G, Ayaz E: Antimicrobial effect of garlic (Allium sativum) and traditional medicine. J Anim Vet Adv 2010, 9:1-4.

4. Booyens J, Thantsha MS: Antibacterial effect of hydrosoluble extracts of garlic (Allium sativum) against Bifidobacterium spp. and Lactobacillus acidophilus. Afr J Microbiol Res 2013, 7:669-677.

5. Booyens J, Labuschagne MC, Thantsha MS: In vitro antibacterial mechanism of action of crude garlic (Allium sativum) clove extract on selected probiotic Bifidobacterium species as revealed by SEM, TEM and SDS-PAGE analysis. Probiotics Antimicrob Proteins 2014, 6:82-87. doi:10.1007/s12602-013-9145-Z

6. Ross FS, Chang SC, Kotik AN, Nadler M, Neuwirth Z, Sundstrom DC, Thompson $\mathrm{NH}$ : In vitro mechanism of inhibition of bacterial cell growth by allicin. Antimicrob Agents Chemother 1988, 32:1763-1768.

7. Al-Waili NS, Saloom KY, Akmal M, Al-Waili TN, Al-Waili AN, Al-Waili H, Ali A, Al-Sahlani K: Effects of heating, storage, and ultraviolet exposure on antimicrobial activity of garlic juice. J Med Food 2007, 10:208-212.

8. Deresse D: Antibacterial effect of garlic (Allium sativum) on Staphylococcus aureus: an in vitro study. Asian J Med Sci 2010, 2:62-65.

9. Gruhlke MCH, Portz D, Stitz M, Anwar A, Schneider T, Jacob C, Schlaich L, Slusarenko AJ: Allicin disrupts the cell's electrochemical potential and induces apoptosis in yeast. Free Radic Biol Med 2010, 49:1916-1924.

10. Focke M, Feld A, Lichtenthaler HK: Allicin, a naturally occurring antibiotic from garlic, specifically inhibits acetyl-CoA synthetase. Fed Eur Biochem Soc 1990, 261:106-108.

11. Lu X, Liu Q, Wu D, Al-Qadiri HM, Al-Alami NI, Kang D-H, Shin J-H, Tang J, Jabal JMF, Aston ED, Rasco BA: Using of infrared spectroscopy to study the survival and injury of Escherichia coli 0157:H7, Campylobacter jejuni and Pseudomonas aeruginosa under cold stress in low nutrient media. Food Microbiol 2011, 28:537-546.

12. Lu X, Rasco BA, Jabal JMF, Aston DE, Lin M, Konkel ME: Investigating antibacterial effects of garlic (Allium sativum) concentrate and garlic-derived organosulfur compounds on Campylobacter jejuni by using fourier transform infrared spectroscopy, Raman spectroscopy, and electron microscopy. Appl Environ Microbiol 2011, 77:5257-5269.

13. Alverez-Ordóñez A, Halisch J, Prieto M: Changes in Fourier transform infrared spectra of Salmonella enterica serovars Typhimurium and Enteritidis after adaption to stressful growth conditions. Int J Food Microbiol 2010, 142:97-105.

14. Zoumpopoulou G, Papadimitriou K, Polissiou MG, Tarantilis PA: Detection of changes in the cellular composition of Salmonella enterica serovar Typhimurium in the presence of antimicrobial compound(s) of Lactobacillus strains using Fourier transform infrared spectroscopy. Int J Food Microbiol 2010, 144:202-207.

15. Al-Qadiri HM, Lin M, Al-Holy MA, Cavinato AG, Rasco BA: Detection of sublethal thermal injury in Salmonella enterica serotype Typhimurium and Listeria monocytogenes using fourier transform infrared (FT-IT) spectroscopy (4000 to $600 \mathrm{~cm}^{-1}$ ). J Food Sci 2008, 73:54-61.

16. Davis R, Mauer $\amalg$ : Fourier Transform Infrared (FT-IR) Spectroscopy: A Rapid Tool for Detection and Analysis of Foodborne Pathogenic Bacteria. In Current Research, Technology and Education Topics in Applied Microbiology and Microbial Biotechnology Volume 2. Edited by Méndez-Vilaz A. Badajoz, Spain: Formatex; 2010:1582-1593.

17. Lu X, Rasco BA, Kang D-H, Jabal JM, Aston DE, Konkel ME: Infrared and Raman spectroscopic studies of the antimicrobial effects of garlic concentrates and diallyl constituents on foodborne pathogens. Anal Chem 2011, 83:4137-4146. 
18. Rault A, Béal C, Ghorbal S, Ogier J-C, Bouix M: Multiparametric flow cytometry allows rapid assessment and comparison of lactic acid bacteria viability after freezing and during frozen storage. Cnyobiology 2007, 55:35-43.

19. Bunthof CJ, Abee T: Development of a flow cytometric method to analyze subpopulations of bacteria in probiotic products and dairy starter. Appl Environ Microbiol 2002, 68:2934-2942.

20. Paparella A, Taccogna L, Aguzzi I, Chaves-López C, Serio A, Marsilio F, Suzzi G: Flow cytometric assessment of the antimicrobial activity of essential oils against Listeria monocytogenes. Food Control 2008, 19:1174-1182.

21. Bunthof CJ, Bloemen K, Breeuwer P, Rombouts FM, Abee T: Flow cytometric assessment of viability of lactic acid bacteria. Appl Environ Microbiol 2001, 67:2326-2335.

22. Marcotte L, Kegelaer G, Sandt C, Barbeau J, Lafleur M: An alternative infrared spectroscopy assay for the quantification of polysaccharides in bacterial samples. Anal Biochem 2007, 361:7-14.

23. Vodnar DC, Paucean A, Dulf FV, Socaciu C: HPLC characterization of lactic acid formation and FTIR fingerprint of probiotic bacteria during fermentation processes. Not Bot Horti Agrobo 2010, 38:109-113.

24. Scherber CM, Schottel JL, Aksan A: Membrane phase behaviour of Escherichia coli during desiccation, rehydration, and growth recovery. Biochim Biophys Acta 2009, 1788:2427-2435.

25. Lin M, Al-Holy M, Al-Qadiri H, Kang D-H, Cavinato AG, Huang Y, Rasco BA: Discrimination of intact and injured Listeria monocytogenes by Fourier transform infrared spectroscopy and principal component analysis. J Agric Food Chem 2004, 52:5769-5772.

26. Volkert M, Ananta E, Luscher C, Knorr D: Effect of air freezing, spray freezing, and pressure shift freezing on membrane integrity and viability of Lactobacillus rhamnosus GG. J Food Eng 2008, 87:532-554.

27. Ananta E, Volker M, Knorr D: Cellular injuries and storage stability of spray-dried Lactobacillus rhamnosus GG. Int Dairy J 2005, 15:399-409

28. Ben Amor K, Breeuwer $P$, Verbaarschot $P$, Rombouts FM, Akkermans AD, de Vos WM, Abee T: Multiparametric flow cytometry and cell sorting for the assessment of viable, injured, and dead Bifidobacterium cells during bile salt stress. Appl Environ Microbiol 2002, 68:5209-5216.

29. Martínez-Abad A, Sánchez G, Lagaron JM, Ocio MJ: On the different growth conditions affecting silver antimicrobial efficacy on Listeria monocytogenes and Salmonella enterica. Int J Food Microbiol 2012. 158:147-154.

30. Da Silva TL, Reis A, Kent CA, Kosseva M, Roseiro JC, Hewitt CJ: Stressinduced physiological responses to starvation periods as well as glucose and lactose pulses in Bacillus licheniformis CCMI 1034 continuous aerobic fermentation processes as measured by multi-parameter flow cytometry. Biochem Eng J 2005, 24:31-41.

31. Shen T, Bos AP, Brul S: Assessing freeze-thaw and high pressure low temperature induced damage to Bacillus subtilis cells with flow cytometry. Innov Food Sci Emerg 2009, 10:9-15.

32. Kim JE, Choi NH, Kang SC: Anti-listerial properties of garlic shoot juice at growth and morphology of Listeria monocytogenes. Food Control 2007, 18:1198-1203.

33. Hayouni EA, Bouix M, Abedrabba M, Leveau J-Y, Hamdi M: Mechanism of action of Melaleucaarmillaris (Sol. Ex Gaertu) Sm. essential oil on six LAB strains as assessed by multiparametric flow cytometry and automated microtiter-based assay. Food Chem 2008, 111:707-718.

34. Schenk M, Raffellini S, Guerrero S, Guillermo AB: Maris Alzamora S: Inactivation of Escherichia coli, Listeria innocua and Saccharomyces cerevisiae by UV-C light: study of cell injury by flow cytometry. Food Sci Technol 2011, 44:191-198.

35. Young KD: Bacterial morphology: why have different shapes? Curr Opin Microbiol 2007, 10:596-600

doi:10.1186/1472-6882-14-289

Cite this article as: Booyens and Thantsha: Fourier transform infra-red spectroscopy and flow cytometric assessment of the antibacterial mechanism of action of aqueous extract of garlic (Allium sativum) against selected probiotic Bifidobacterium strains. BMC Complementary and Alternative Medicine 2014 14:289.

\section{Submit your next manuscript to BioMed Central and take full advantage of:}

- Convenient online submission

- Thorough peer review

- No space constraints or color figure charges

- Immediate publication on acceptance

- Inclusion in PubMed, CAS, Scopus and Google Scholar

- Research which is freely available for redistribution 